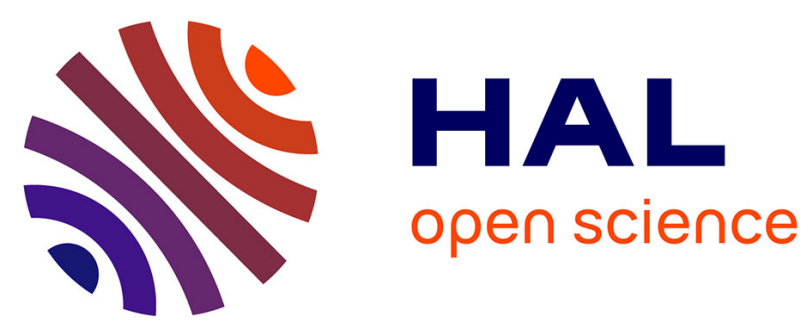

\title{
Towards a Cognitive Linked Public Service Cloud
}

\author{
Santiago Salem, Adegboyega Ojo, Elsa Estevez, Pablo R. Fillottrani
}

\section{To cite this version:}

Santiago Salem, Adegboyega Ojo, Elsa Estevez, Pablo R. Fillottrani. Towards a Cognitive Linked Public Service Cloud. 19th Working Conference on Virtual Enterprises (PRO-VE), Sep 2018, Cardiff, United Kingdom. pp.430-441, 10.1007/978-3-319-99127-6_37 . hal-02191192

\section{HAL Id: hal-02191192 \\ https://hal.inria.fr/hal-02191192}

Submitted on 23 Jul 2019

HAL is a multi-disciplinary open access archive for the deposit and dissemination of scientific research documents, whether they are published or not. The documents may come from teaching and research institutions in France or abroad, or from public or private research centers.
L'archive ouverte pluridisciplinaire HAL, est destinée au dépôt et à la diffusion de documents scientifiques de niveau recherche, publiés ou non, émanant des établissements d'enseignement et de recherche français ou étrangers, des laboratoires publics ou privés. 


\title{
Towards a Cognitive Linked Public Service Cloud
}

\author{
Santiago Salem ${ }^{1}$, Adegboyega $\mathrm{Ojo}^{2}$, Elsa Estevez ${ }^{1,3}$, Pablo R. Fillottrani ${ }^{1,4}$ \\ ${ }^{1}$ Dep. of Computer Science and Engineering, Universidad Nacional del Sur, Bahía Blanca, \\ Argentina \\ ${ }^{2}$ Insight Centre for Data Analytics, National University of Ireland Galway, Galway, Ireland \\ ${ }^{3}$ Institute for Computer Science and Engineering (UNS-CONICET) \\ ${ }^{4}$ Comisión de Investigaciones Científicas de la Provincia de Buenos Aires, Argentina
}

salem_santiago@hotmail.com, adegboyega.ojo@insight-centre.org, \{ece,prf\}@cs.uns.edu.ar

\begin{abstract}
Cognitive computing applications are steadily growing across sectors and increasingly considered for adoption in government for transforming public services. Semantic technologies have been identified as one of the enabling technologies for cognitive computing capabilities. This paper describes some foundational efforts for the deployment of ontological semantics-driven cognitive capabilities in delivering a family of public services. First, we present an application profile for the Core Public Service Vocabulary extending the core vocabulary into a rich domain ontology - Social Welfare Service Ontology. Second, we use the Social Welfare Service domain ontology to as a basis for the design of a Linked Public Service Cloud. The proposed Cloud comprises a detailed description of concrete instances of social welfare services and links (relationship) between such services. By linking services across linked public service clouds associated with different public administrations, like different municipal governments, we demonstrate how cognitive capabilities supporting citizen requests could be realized through reasoning and propagation of information over semantic networks of public service clouds.
\end{abstract}

Keywords: Linked Data; Cognitive Applications; Linked Public Service Cloud; Ontologies; Semantic Technologies

\section{Introduction}

Whole-of-Government (WoG) and Networked Governance approaches are increasingly adopted in public administrations to enable collaboration across agency boundaries and with third-parties parties for access to external resources and rapid innovation. These approaches require for support shared and connected information and technology infrastructure across and beyond government. For instance, in Networked Governance, public technological platforms that are able to connect citizens and other external parties to government agencies (e.g. social media platforms) are critical for enabling interaction. In the context of the WoG, shared services and service catalogs describing and relating services exemplify enabling infrastructure for joined-up and coordinated service delivery. 
416 S. Salem et al.

With the recent upsurge in interest in Artificial Intelligence, Cognitive computing, Big Data Analytics, governments like the private sector have begun to seriously explore how to effectively harness these disruptive technologies in building smarter services and infrastructure that are able to respond better to citizens needs. Evidence of this interest is captured in [1] where the potential applications areas of Cognitive computing in the public sector were articulated.

Cognitive computing aims to mimic the human process of knowing and problemsolving and decision making based on the perception and understanding of concepts. Cognitive systems offer four main capabilities [1] [2]: 1) understanding - the process of comprehending different types of data, like pictures and text; 2) reasoning - the process of inferring a conclusion based on information that has been previously analyzed; 3) discovery - reading and identifying patterns over huge amount of data in faster ways than humans can do; 4) learning - acquiring knowledge from different sources helping to reduce mistakes in future decisions. Given their valuable capabilities, cognitive computing applications are steadily growing across sectors and increasingly considered by governments for transforming public services. As it is explained knowledge-workers use 2.5 hours per day looking for information and such time could be reduced by $50 \%$ using appropriate cognitive applications [3].

Cognitive systems employ different techniques and tools to extract information from unstructured sources using Natural Language Processing techniques. One of the main challenges in NLP is related to semantics. Semantics enables defining concepts (.e. their meaning) and the existing relations between them. To formally represent semantics, ontologies provide a mechanism for specifying and capturing the knowledge of a specific domain in machine-readable form. Consequently, semantics and ontologies play an important role in cognitive systems because they facilitate some tasks of NLP; enabling cognitive systems to understand and reason, as human beings do, facilitating the understanding of concepts by computers.

In this paper, we demonstrate the centrality of semantics and ontology in enabling cognitive capabilities in shared government information and service infrastructure. Specifically, we show how cognitive capabilities in public service cloud infrastructure underpinned by an ontology of social welfare public services can enhance government efficiency and contribute to improving the delivery of public services to citizens. In this context, the public service ontology enables two cognitive features: 1) acts as the memory or internal knowledge base and 2) affords the mechanism for reasoning to solve problems such as service eligibility decisions and discovery of relevant services for the government customer - the citizen.

The rest of this paper is structured as follows. Section 2 introduces cognitive technologies and their usage in government. Section 3 presents an ontology for welfare public services and explains cognitive capabilities offered by the ontology. Section 4 builds the concept of cognitive linked service cloud based on the capabilities offered by the ontology introduced in Section 3. Section 5 explains scenario for the usage of such tools in collaborative government networks. Finally, Section 6 discusses and concludes the paper. 


\section{Cognitive Technologies in Government}

The term Cognitive Technologies was coined various decades ago and despite the regular appearance of new technologies which makes such technologies to vary and progress in a steady way, the term remains actual and relevant. In particular, the development of cognitive technologies was initially envisioned in the 1978 Practical Aspects of Memory Conference [4]. Later, in 1995, the Ontario Institute for Studies in Education defined them as those that transcend typical human cognitive limitations like memory [5]. A recent definition explains that they refer to technologies that directly or indirectly affect learning, retention, remembering, reasoning, and problemsolving [4]. Currently, cognitive technologies are applied to many issues of our daily life. For instance, such technologies are used by software applications providing us information about the conditions of our daily trips to commute from one place to another; to keep track and remind us about our appointments and planned events; to inform us about weather conditions; and to detect if an illegal transaction was conducted by a given customer; among other examples.

Government is a main application area for cognitive technologies. In particular, new innovative and smart services, such as personalized, anticipated, context-aware and context-intelligent services [6] can be delivered and their delivery can be improved through the use of cognitive technologies. For example, [7] introduces a chatbot $^{1}$-based prototype for assisting users in retrieving and analyzing open data in a friendly way. Chatbots are developed using a combination of various technologies, like pattern matching, parsing, artificial intelligence, machine learning and ontologies [7]. Another technology, text mining is utilized for analyzing textual data provided in the form of opinions or complaints by the public in government systems to detect improvement areas in service delivery [8][9]. In addition, a service ontology has been enhanced with a semantic approach to support various usage contexts and scenarios for public services. In this case, the proposed solution contributes to improving the level of automation of the discovery and composition processes of public services [9].

\section{Semantics-driven Cognitive Capabilities in Welfare Service Management}

This section presents the conceptual framework used for defining the vocabulary (Section 3.1), the ontology for public services, in particular, the ontology for welfare public services (Section 3.2) and its formalization through an ontology authoring tool (Section 3.3).

\footnotetext{
${ }^{1}$ A chatbot is a computer program able to maintain a conversation with a user, either through text or voice.
} 


\subsection{Conceptual Framework}

The framework identifies main concepts related to the delivery of public services. The model is based on previous studies [10] [11] [12][13] [14] which identify and describe common concepts for the provision of seamless public services. Figure 1 synthesizes the concepts that are later extended for the specific case of Welfare Public Services.

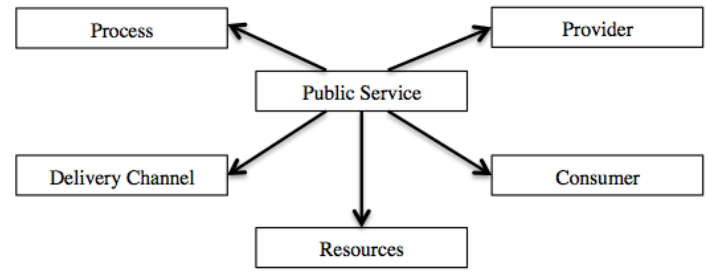

Fig. 1 Conceptual model

Terms included in the conceptual model are explained as follows: Public Service - is a service performed for the benefit of the public, especially provided by a non-profit organization; Provider - is the entity responsible for providing the service; Consumer is an individual that receives the public service ; Resources - comprises all assets and other resources used for providing the service; Delivery Channel - refers to the means used by the provider to deliver the public service to the consumers; and Process comprises all the activities necessary to produce as final output the provision of the public service to the consumers.

\subsection{Vocabulary and Ontology Design}

Local governments use different approaches to describe their public services. This refers both, to the terms of the vocabulary but also to how much details they include in such descriptions. In addition, service descriptions are usually provided using free narrative forms and in the same government unit, they highly differ in the way they are written.

One of the tasks of this research was to identify and understand the vocabulary that captures common concepts and features of social welfare services. To address this challenge, we conducted a survey among representatives of two local governments in Buenos Aires Province, Argentina - Bahía Blanca and La Plata. The survey was carried out online, implemented using an open source tool (LimeSurvey), and also through an offline version implemented in Microsoft Word. It was conducted during June-July 2017 in Bahia Blanca, and during September-October 2017 in La Plata. The collected answers were related to 20 welfare public services.

Based on the conceptual -framework described before, the services identified through the survey, and the interactions with representatives of both municipal governments, we defined an initial set of vocabulary terms (see Figure 2). Using the set of terms, the second step was to extend the vocabulary based on local and sectorial features and also extending it using the Core Public Service Vocabulary - CPSV (see Figure 3), an ontology that captures key concepts about public services, like for example, related to the legal basis for the provision of the service, contact point and 
opening hours, the output delivered by the service and other data.

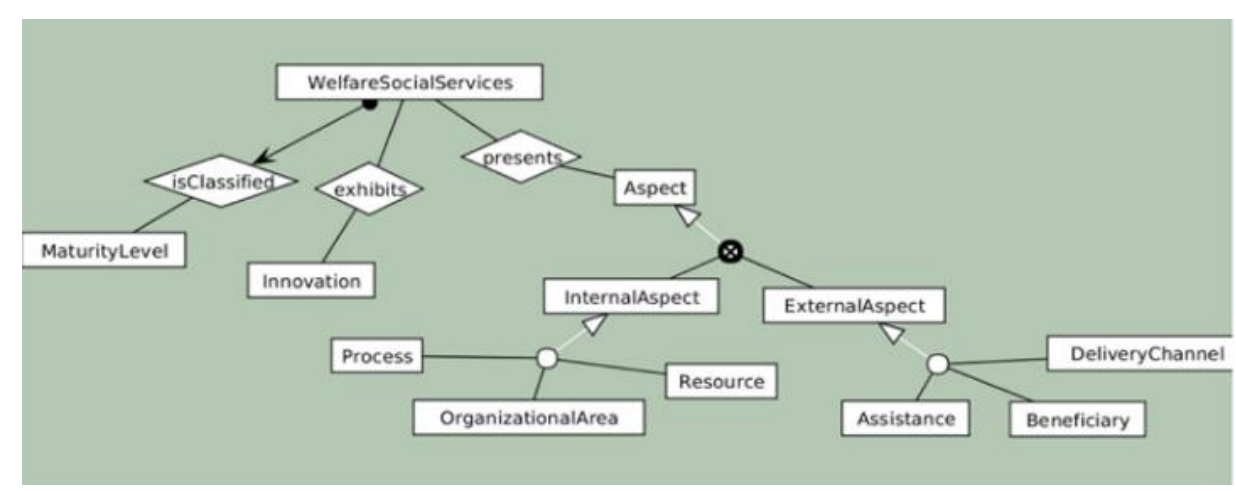

Fig. 2 Welfare Public Services - Initial Vocabulary

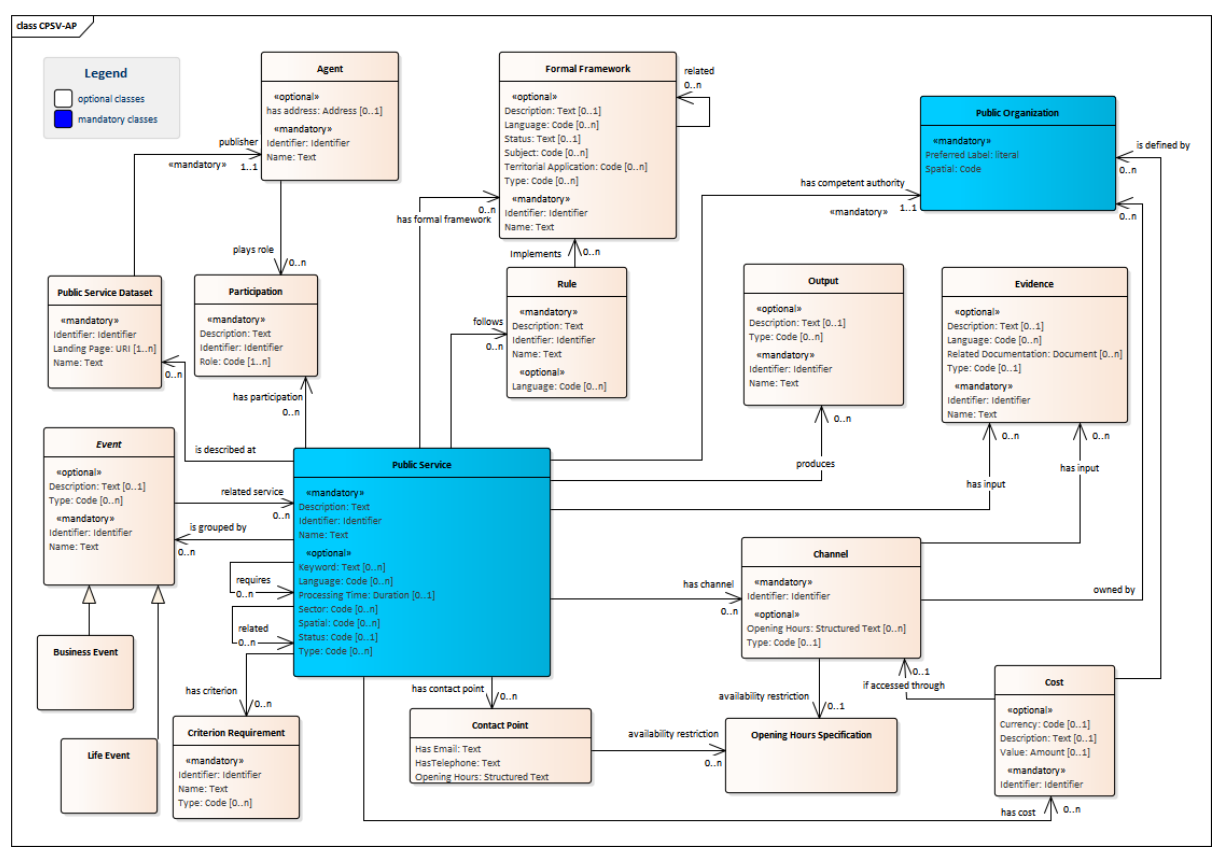

Fig. 3 Core Public Service Vocabulary 


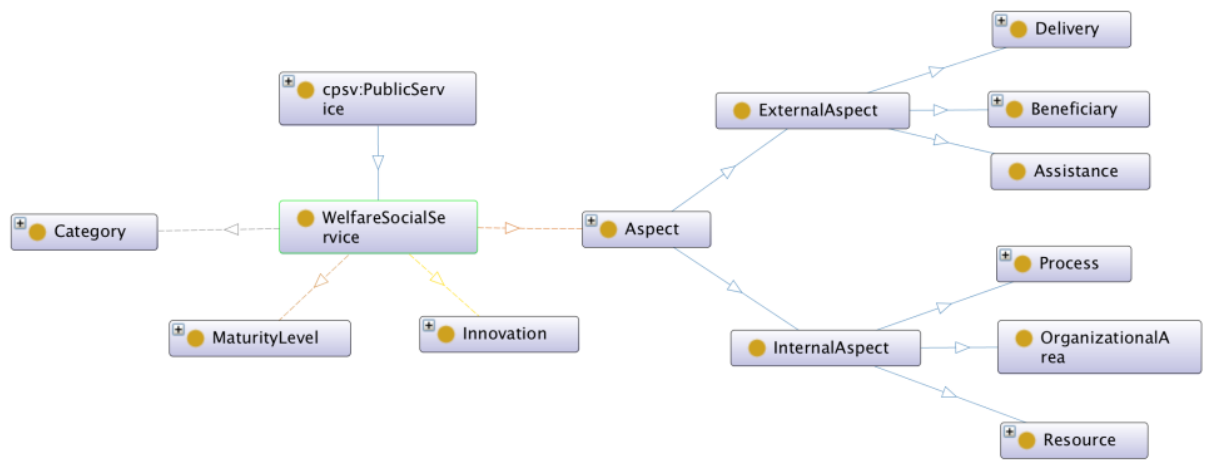

Fig. 4 Core Public Service Vocabulary Application Profile for Welfare Services

Considering that cognitive systems need to have all concepts defined with formal semantics and machine-readable descriptions of the services for proper understanding, we design an ontology in the next step. The proposed ontology captures common concepts - e.g. Assistance, Beneficiary, Maturity Level and attributes required for the complete description of a Welfare Public Service, including aspects that are of special interest for the back-office and front-office applications and processes.

The ontology up to the third level is presented in Figure 4 and the object properties in Table 1. Each of the concepts included in the ontology is explained as follows. WelfareSocialServices - represents any welfare public service provided by a local government and is an extension of the Public Service defined in the Core Public Service Vocabulary; Category - represents the specific type of the service provided possible values are: unemployment, teenagers, pregnant, elderly people, and furthermore. MaturityLevel - refers to the service maturity level. Possible values include: informational, interactive, transactional and connected. Innovation - refers to the type of innovation applied by the service. Possible values include those in [6]; Aspect - depicts a feature of a service. It could be internal or external; InternalAspect corresponds to any service feature that is not visible to the public; ExternalAspect refers to any service feature visible to the public; Process - comprises the activities performed by the service provider. It could be ApplicationProcess or DeliveryProcess. ApplicationProcess - refers to all the activities that should be done when an individual decides to enroll in a welfare public service. DeliveryProcess corresponds to all the activities that should be completed to bring the benefit to the beneficiary. ElegibilityCriteria - comprises all the requirements that the individual must fulfill to become a beneficiary. OrganizationalArea - identifies the government organizational unit response for the service provision; Resourse - refers to any kind of resource used for producing and delivering the service. It could be human, financial, technical or organizational. Human - refers to all the people that is involved in the process. Financial - refers to the money received to provide the service and it could come from the national, province or local government. Technical - comprises any kind of technical device or equipment used for the business process underpinning the service provision. Organizational - refers to the strategy and plans that are followed for the service provision and delivery. Assistance - identifies the type of benefit received; Beneficiary - represents the service recipient. It could be a household or a 
person. Household - refers to a whole family or group of individuals that live in the same house and receive a benefit. Person - refers to an individual; and Delivery comprises the channels used to deliver a service and the specific range of time in which the service will be available. DeliveryChannel - refers to the means used to deliver the service. DeliveryDate - comprises the date when the service was delivered for the first time and when will be finished, and data on how periodically the assistance is delivered to the beneficiaries.

Table 1. Welfare Public Services Vocabulary - Object properties.

\begin{tabular}{llll}
\hline Object property & Domain & Range & Is inverse of \\
\hline hasCategory & WelfareSocialService & Category & isCategoryOf \\
\hline isClassified & WelfareSocialService & MaturityLevel & classifiedBy \\
\hline Exhibits & WelfareSocialService & Innovation & exhibitedBy \\
\hline Presents & WelfareSocialService & Aspects & belongsTo \\
\hline hasDeliveryDate & Delivery & DeliveryDate & isDeliveryDateOf \\
\hline hasDeliveryChannel & Delivery & DeliveryChannel & isDeliveryChannelOf \\
\hline
\end{tabular}

\subsection{Implementation}

After defining the ontology, we formalize it through a software tool. For this, we used Protégé, a well-known ontology editor that has the advantage of being free and opensource. The formal definition of the ontology enables to more rigorously describe each public welfare services, and to publish more reliable data as open data through the local government portal.

\section{Cognitive Linked Service Cloud}

This section presents the evolution of the developed ontology through a Welfare Service Cloud (Section 4.1), to a Cognitive Welfare Service Cloud in which the cognitive features are enacted in a specific application context (Section 4.2).

\subsection{From Welfare Social Ontology to Welfare Service Cloud}

Based on the Welfare Public Service Ontology defined in Section 3, each agency can define instances of such ontology with the different welfare public services that they deliver. With such instantiations, a public administration jurisdiction (e.g. local or state authority) can have a Welfare Service Cloud, in other words, a data space used for storing all the services described using the ontology. It is also possibly for the concrete individuals or instances of the Welfare Public Service Ontology to be automatically acquired through information extraction (NLP based process) from government public service portals (we shall return to this point in our discussion). The 
model is shown in Figure 5. In the depicted model, there is a government cloud, where information about services is stored and managed (Service Cloud). We can also envisage the service cloud to be integrated to information systems in government agencies supporting the production and delivery of welfare services. In particular, a subset of such services is the Welfare Public Services. Data stored for each of the services can be linked - e.g. services delivered to the same citizen (shown as internal links in the figure) or services related to other services. Such Welfare Service Cloud is accessed and managed by all government units or entities of the same public administration, who are the providers of the services in the cloud.

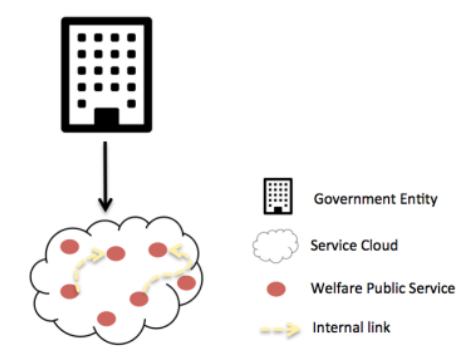

Fig. 5 Welfare Service Cloud

\subsection{From Welfare Service Cloud to Cognitive Linked Service Cloud}

Adding one more layer of integration, we may consider linking the Welfare Service Clouds managed by local governments. This is realised by linking ontologies in two or more Welfare Service Clouds. For instance, service clouds in two different local authorities could be linked by relating similar or equivalent services in the different clouds. This integration further strengthens the cognitive capability potentials of the Service Clouds and enables governments to deliver seamless services regardless the public administration jurisdiction that are involved. By linking the welfare service clouds it would be possible to have access to significant amount of data, and through cognitive systems, to produce data supporting evidence-based public policies. A schema of this concept is shown in Figure 6.

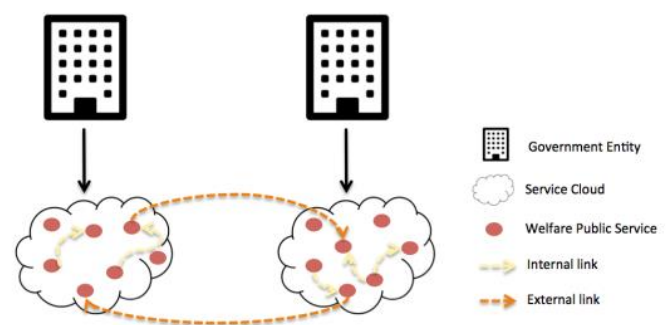

Fig. 6 Cognitive Linked Service Cloud 


\section{Scenarios for Exploring the Cognitive Linked Service Cloud}

The objective of this section is to explain the process for using the cognitive linked service cloud and to present a concrete scenario illustrating its potential.

\subsection{Process}

The Welfare Public Service that each government entity delivers is described using the Core Welfare Public Service Vocabulary. Each of such description constitutes an instance of the ontology that is stored in the Welfare Service Cloud. The ontology enables linking services, and the use of linked services allows government entities to improve their service delivery and opens up opportunities for developing new applications that can take advantage of it, like those supporting the delivery of seamless services or evidence-based policy-making.

\subsection{Scenario - Decision Making \& Discovery of Services in inter-linked clouds}

As explained in Section 4, each Welfare Service Cloud can have internal and external links to similar services. To demonstrate the importance of such links and of having the welfare services documented in the Welfare Service Cloud, consider a citizen looking for information about services. He uses the Government Mobile App that provides an interface to query the Welfare Service Cloud of his local government. He is unemployed and wants to know if he is eligible for the unemployment benefit that his local government is delivering ${ }^{2}$. The program is called "Insurance for Training and Employment". The aim of the program is to help unemployed people to acquire new skills so they can apply for a new job. The program also provides advice for finishing previous studies. The citizen ticks the requirements that he fulfilled and with that information, using existing rules and internal linked data in the cloud, for instance, enabling to check the applicant's education, history of previous works, and previous services received from this program, the system exploiting its cognitive capabilities is able to determine whether the applicant is eligible for the benefit or not.

The citizen still has some doubts. He will be moving to Buenos Aires in the next three months and wants to know if there is some similar benefit in that city. Using the mobile app, the system is able to discover similar services using the external links (see Fig. 7). The app showed a social benefit delivered by the government of the City of Buenos Aires. The benefit is called "Training and Inclusion for Work" citizen ticks for applying for the benefit. The system applies the rules to check if the citizen is eligible to receive that benefit and after the processing, the system popped up that he is not eligible. Although, the citizen fulfills most of the requirements, he does not satisfy the requirement that says "minimum, immediate and uninterrupted

2 Government of Municipality of Bahia Blanca, government website for employment. http://www.bahia.gob.ar/empleo/ (visited 14-07-2018).

3 Government of Municipality of Buenos Aires, government website for employment, http://www.buenosaires.gob.ar/desarrollohumanoyhabitat/economiasocial/programafit (visited 14-07-2018). 
residence of 2 years in the City of Buenos Aires". However, the system continues the discovery process searching for a service that could fit the needs of the citizen. The system found a third service called "Insurance of Training and Employment".

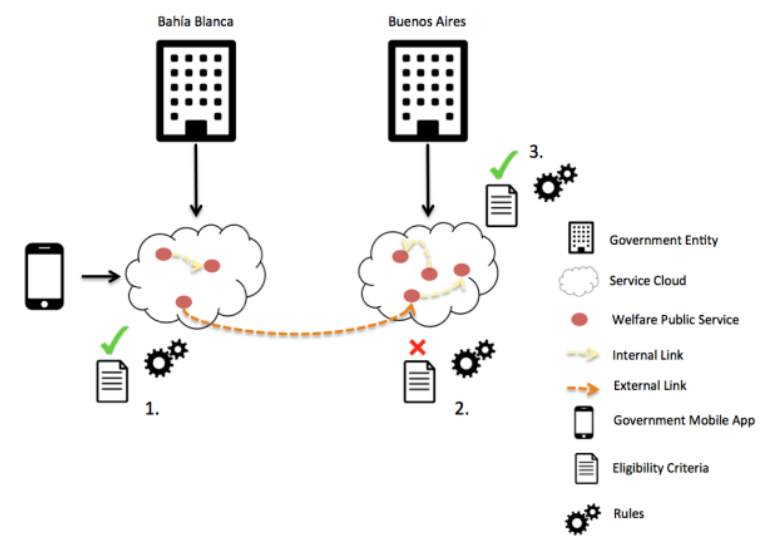

Fig. 7 Scenario proposed

The benefit provides training and financial help for persons who are actively looking for a job. The requirements are the following: 1) being over 18 years old; 2) in case of being under 25 years old, having the studies of the secondary school finished; 3 ) being unemployed and being actively looking for a job; 4) being a permanent resident in the country; 5) having a national identity document; 6) being in the group of unemployed persons and 6) not receiving another assistance or benefit from the National, Provincial or local Governments, except those granted to veterans of the Malvinas war. The citizen ticked the requirements he fulfilled and then the system process that data taking into account the rules presented and validating the information using external links of the clouds. The system showed to the citizen that he is able to receive the benefit.

In the scenario defined above, we can see two important cognitive capabilities, discovery and reasoning. Discovery is the process of searching through huge amount of data in faster ways that humans can do. The links that exist between services, let the system discover similar services that could be stored in the same Welfare Service Cloud or it could be stored in an external cloud. If this task should be done manually, it would be slower than using the system, the employee should search over all the social services, understand them and decide if they are or not similar. This process is done faster than a human being could do. Furthermore, the capability of reasoning is also present in the scenario. Reasoning is the process of arriving to a conclusion after analyzing information that is served as an input. When the citizen wants to know if he or she is eligible for certain social service, the system is the responsible of taking into account the socio-economics characteristics of the citizen and, using the existing rules, it is able to reason and decide if the citizen could apply to a specific social

\footnotetext{
${ }^{4}$ Argentinean National Government, Capacity-building portal, https://www.argentina.gob.ar/acceder-al-seguro-de-capacitacion-y-empleo (visited 15-042018).
} 
service. In this scenario, we are helping in the process of decision making, making it easier and faster than if should be done by humans.

\section{Discussion \& Conclusion}

Implementing the above scenario based on the state-of-the-art government information and service infrastructure will be extremely difficult. The reasons are due to the nature of the implementation of public service delivery platforms and lack of integration across public administration jurisdiction and levels of government. We have shown that through a linked catalog of public services constituting a service cloud and the cross-linking of two or more service clouds, citizens information and decision needs can be better met. In summary, Cognitive features of perception or input could be realized through the automatic population of welfare service ontology through information extraction process. The relationship between services could be deduced using named entity extraction tools for identifying public services names in documents describing public service on government portals. Relating services is achieved by linking the uniform resource identifiers (URIs) of services. The reasoning is enabled through the rules in the welfare service ontology and problem-solving is made possible by combining the reasoning capability with access to sources of citizen information through interfaces provided by government information systems.

We can thus argue that that semantic technologies play an important role in cognitive systems. We defined the concept of Welfare Service Cloud and extended it to Cognitive Linked Service Cloud, where semantics helps to understand the meaning of the services described. However, we note that semantics and ontologies need to be supported with text-mining techniques such other natural language processing tools for realizing semantic-driven cognitive capabilities in real applications like the scenario described in Section 5. We conclude that integrating the semantic web with requisite complementary technology can deliver cognitive capabilities for networks of collaborative systems.

In our view, the contributions of this work are: a) illustrating how an ontology serves as a foundational component of a cognitive system; b) providing a concrete scenario and use case for the application of semantics-driven cognitive systems in government collaborative networks; and c) development and implementation of an application profile for the Core Public Service Vocabulary Application for the domain of Social Welfare Services. We believe that our concept of Cognitive Linked Service Cloud concept has major implications for regional initiatives such as the European Single Market where European citizens freely moving across borders of European nations still require access to services in their home countries.

\section{References}

[1] W. and S. \& Analytics, "Your cognitive future Part I: The evolution of 
cognitive." 2015.

[2] M. Beetz, M. Buss, and D. Wollherr, "Cognitive technical systems-what is the role of artificial intelligence?," KI 2007 Adv. Artif. Intell., 2007.

[3] N. Tahamtan, "How Semantic Technologies Enable Domain Experts to Steer Cognitive Applications," 2017.

[4] W. R. Walker and D. J. Herrmann, Cognitive Technologies, Essays on the Transformation of Thought and Society. McFarland \& Company, Inc., 2005.

[5] T. Greening, "Building the Constructivist Toolbox: An Exploration of Cognitive Technologies," Educ. Technol., vol. 38, no. 2, pp. 23-35, 1998.

[6] J. Bertot, E. Estevez, and T. Janowski, "Universal and contextualized public services: Digital public service innovation framework," Gov. Inf. Q., vol. 33, no. 2, pp. 211-222, 2016.

[7] S. Porreca, F. Leotta, M. Mecella, S. Vassos, and T. Catarci, "Accessing Government Open Data Through Chatbots," in Proceedings of the International Workshop on the Practice of the Open Web (practi-O-web 2017), 2017, no. June 2017, pp. 156-165.

[8] I. Surjandari, C. Megawati, A. Dhini, and I. B. . Sanditya Hardaya, "Application of text mining for classification of textual reports: A study of Indonesia's national complaint handling system," in Proceedings of the International Conference on Industrial Engineering and Operations Management, 2016, pp. 1147-1156.

[9] D. Narinam, "Analyzing text-based user feedback in e-Government services using topic models," in Proceedings - 2013 7th International Conference on Complex, Intelligent, and Software Intensive Systems, CISIS 2013, 2013, pp. $720-725$.

[10] A. Ojo, T. Janowski, and E. Estevez, "A Composite Domain Framework for Developing Electronic Public Services." in SETP, pp. 234-241. 2007.

[11] A. Ojo, T. Janowski, and E. Estevez, "Domain Models and Enterprise Application Framework for Developing Electronic Public Services," in Proceedings of the 6th International EGOV Conference, 2007, pp. 157-164.

[12] T. Janowski, A. Ojo, and E. Estevez, "Rapid Development of Electronic Public Services - Software Infrastructure and Software Process," Technology, pp. 294-295.

[13] T. Janowski, A. Ojo, and E. Estevez, "Rapid Development of Electronic Public Services - A Case Study in Electronic Licensing Service," Architecture, pp. 292-293.

[14] E. Estevez, P. Fillottrani, and T. Janowski, "From e-Government to Seamless Government," Conf. Collab. Electron. Commer. Technol. Res. (CollECTeR Iberoamerica 6-9 Novemb. 2007), pp. 269-280, 2007. 